- had been promised and made a worrying number of errors. But Oxford Nanopore has made improvements; recent publications by pilot users have shown that a MinION can do quite a lot. It can reliably sequence small genomes, such as those of bacteria and yeast. It can discriminate between closely related bacteria and viruses, read complex portions of the human genome, and differentiate between the two versions of a gene that are carried on each chromosome pair.

\section{SEQUENCING ON THE FLY}

Oxford Nanopore's progress has some biologists imagining new ways to use sequencing in the field. On 4 May, Italian biologists toted MinIONs and other equipment into a rainforest in southern Tanzania to sequence the genome of a native frog. Karen James at the MDI Biological Laboratory in Bar Harbor, Maine, wants to put it in the hands of citizen scientists to survey biodiversity in Maine's Acadia National Park. If Oxford could modify the MinION to run on an iPhone, an app written by computational biologist Michael Schatz at Cold Spring Harbor Laboratory in New York might enable onthe-spot identification of unknown organisms using just the two hand-held devices. NASA scientists even plan to send a MinION to the International Space Station, where astronauts would test it in microgravity. If that goes well, astrobiologist Aaron Burton at the Johnson Space Center in Houston, Texas, suggests that a hand-held sequencer might be sent to Mars to look for molecular signs of life on the red planet.

Yet there is still plenty that the MinION cannot do. It is not practical to sequence large genomes with the device: Schatz estimates that it would take a year for the current version to sequence the equivalent of a human genome. And the machine still misidentifies DNA sequence $5-30 \%$ of the time - a high error rate compared with those of existing fullsized sequencers. It also has problems reading regions of sequence where long stretches of the same DNA base are common.

Improvements are coming: the MinION reads each genetic base many times, and bioinformaticians in the pilot programme have developed error-correcting methods to combine data from these reads into results that have a much lower overall error rate.

Biologists want more from the MinION faster and more accurate performance, and the ability to simply drop a sample onto the sequencer with no preparation. Users hope that, at the London meeting, the company will unveil improvements in the speed and performance of the technology that it has hinted at on Twitter over the past month. The commercial price is also a big unknown; low cost is a huge part of the device's appeal, but Oxford will need to prove to its investors that they can still make money selling devices cheaply. If, as Deamer says, biologists are on a high right now, the company still has much to do to keep the buzz from fading..

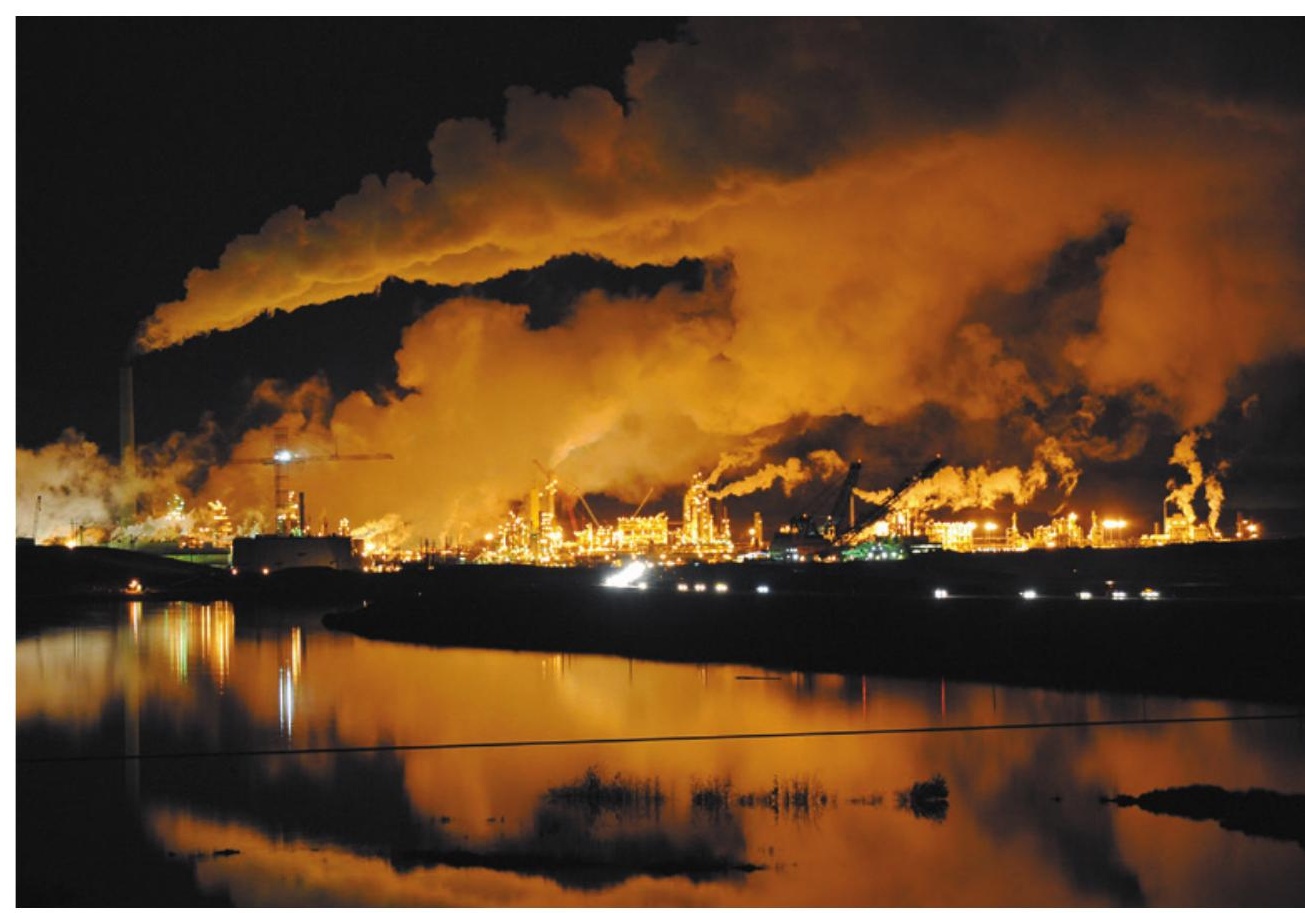

Fossil-fuel energy is a profitable business, but institutions are being urged not to invest in it.

POLICY

Reality check for
fossil-fuel divestment

Academics urge other ways to reduce carbon emissions.

\section{BY JEFF TOLLEFSON}

卫 The fossil-fuel divestment movement has divided academia. On 24 April, SOAS University of London announced that it would sell off all of its investments in fossilfuel companies within three years. Days later, the New York University (NYU) senate voted to recommend that the university keep its current fossil-fuel investments, but to develop a greener strategy for the future. Other institutions, including Harvard University in Cambridge, Massachusetts, and most recently Swarthmore College in Pennsylvania, have rejected calls for divestment.

Even if the movement does convince institutions to pull billions of dollars out of fossil fuels, economists generally agree that divestment will have little impact on the energy industry or greenhouse-gas emissions. Supporters themselves acknowledge that it is mostly a symbolic gesture. But some academics fear that the movement could draw attention away from more effective ways to encourage low-carbon energy.

"We need to focus on actions that are going to make a real difference," says Rob Stavins, an economist at Harvard.

Students and environmentalists launched the divestment movement a few years ago, targeting major institutional investors such as public pension funds, government-held investment funds and philanthropic foundations. Organizers say that nearly 30 universities worldwide have made commitments to divest, or to otherwise revise their investment strategies. But investment experts say that divestment is unlikely to make a difference. "We don't believe in divestment as a strategy - it's naive, and it doesn't solve the problem," says Julian Poulter, chief executive of the Asset Owners Disclosure Project in London, which works with institutions to build greener investment portfolios to reduce risk as governments impose emissions-reducing regulations.

At NYU, faculty members, students and administrators in its 129-person senate adopted a resolution suggesting that the board of trustees maintain fossil-fuel investments totalling roughly US $\$ 139.7$ million — around $4.1 \%$ of the $\$ 3.4$-billion endowment. However, the resolution calls on the university not to put further money into fossil-fuel companies, and instead to develop a plan to invest in firms that 
"demonstrate a commitment to mitigate the effects of burning fossil fuels".

"I'm happy with this outcome; it's a sign of progress," says David Frank, an environmental ethicist at NYU. He signed a petition in support of divestment, and says that the campaign is raising awareness about the problem, even if it does not provide any specific solutions.

Others complain that divestment misses the central role of fossil fuels in modern life. "How can you vilify the consumption of something that you use every day?" says Frank Wolak, an economist at Stanford University in California.

He and others hope to shift students' attention to what they consider a more effective strategy for weaning universities - and the world — off fossil fuels. On 20 April, Yale University in
New Haven, Connecticut, announced plans to develop an internal carbon tax to reduce emissions. Wolak has proposed a similar approach at Stanford, and his team aims to develop a network of universities dedicated to the idea.

Such a network will not have a major impact on global carbon dioxide emissions, but economists have called for the same approach on a global scale. If fossil-fuel emissions were assigned a fee on the basis of their environmental impact, then dirty energy would become more expensive than cleaner alternatives. That would naturally shift investment toward cleaner sources.

At Yale, the carbon fee would be revenue neutral, similar to national proposals from think tanks in Washington DC. Money would be transferred from departments that have higher greenhouse-gas emissions than the university average to those that perform better. Students could participate by helping to cut emissions.

The idea is to give students and faculty members experience that they can carry into the real world, says William Nordhaus, an economist at Yale who led the development of the proposal. Nordhaus expects the university to start a pilot programme in the coming academic year, and to expand to all operations within three years.

"If you want to do something about climate change, then you have to do something about prices," he says. "You are not going to solve the problem by beating up on companies." SEE EDITORIAL P.6

\section{BY DAVIDE CASTELVECCHI}

I $t$ is one of the most disputed observations in physics. But an explanation may be in sight for a mysterious excess of high-energy photons at the centre of the Milky Way. The latest analysis ${ }^{1}$ suggests that the signal could come from a dark-matter particle that has just the right mass to show up at the world's largest particle accelerator.

The Large Hadron Collider (LHC), housed at the CERN particle-physics laboratory near Geneva, Switzerland, is due to restart colliding protons this summer after a two-year hiatus. Physicists there have told Nature that they now plan to make the search for such a particle a top target for the collider's second run.

A positive detection would resolve the source of the galactic $\gamma$-rays. But it would also reveal the nature of dark matter, the invisible stuff thought to make up around $85 \%$ of the Universe's matter, and would be long-sought evidence for supersymmetry, a grand way to extend the current standard model of particle physics.

"This could very well be the single most promising explanation for the Galactic Centre proposed to date," says Dan Hooper of the Fermi National Accelerator Laboratory (Fermilab) in Batavia, Illinois, although he adds that "there are quite a few others that are not too far behind".

In 2009, Hooper and Lisa Goodenough, then a graduate student at New York University, were the first to spot the signal ${ }^{2}$, in data from NASA's Fermi Gamma-Ray Space Telescope. They proposed that the bump was a signature of dark matter. Two colliding dark-matter particles would annihilate each other, just as ordinary matter does with antimatter. The annihilation would generate a succession of short-lived particles that would eventually produce $\gamma$-rays.

But the proposed particle, which has been dubbed the hooperon or gooperon after its proponents, soon ran into problems with physicists' favourite version of supersymmetry. Although the minimal supersymmetric standard model (MSSM) allows for dark-matter particles with the estimated mass of hooperons - about $25-30$ gigaelectronvolts $(1 \mathrm{GeV}$ is roughly the mass of a proton) - multiple experiments had suggested that the particles must be heavier. To accommodate hooperons, MSSM would have to be modified to an extent that makes many physicists uncomfortable. "It would have required a completely new theory," says Sascha Caron, a particle physicist at Radboud University Nijmegen in the Netherlands, who leads the team behind the latest calculations.

Sceptics suggested that the $\gamma$-ray excess spotted in the Fermi data had more-mundane explanations, such as emissions from neutron stars or from the remnants of exploded stars.

But in late 2014, it emerged that calculations for the range of dark-matter-particle masses

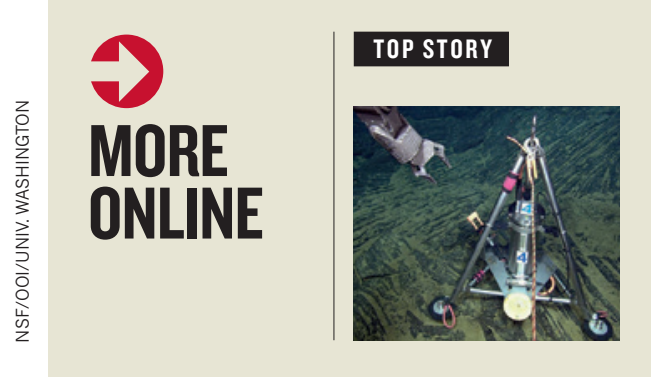

\begin{tabular}{|c|c|}
\hline $\begin{array}{l}\text { Massive } \\
\text { underwater } \\
\text { volcano tests } \\
\text { observing } \\
\text { network } \\
\text { go.nature.com/ } \\
\text { juacyy }\end{array}$ & $\begin{array}{l}\text { - Staff at Australian science agency } \\
\text { start industrial action go.nature.com/3frocl } \\
\text { - Floods might have doomed ancient } \\
\text { American city go.nature.com/4nkcbo } \\
\text { - First results from psychology's } \\
\text { largest reproducibility test go.nature. } \\
\text { com/vjixtl }\end{array}$ \\
\hline
\end{tabular}

\section{MORE NEWS}

- Staff at Australian science agency start industrial action go.nature.com/3froc - Floods might have doomed ancient American city go.nature.com/4nkcbo First results from psychology's $\mathrm{com} / \mathrm{vjixtl}$

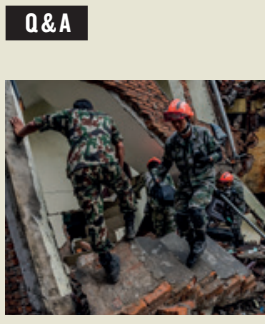

How scientists are aiding quake recovery in Nepal go.nature. com $/ 3$ mdjma 